\title{
BMJ Open Patient-centred infertility care among Arab women experiencing infertility: a qualitative study
}

\author{
Hana Hasan Webair (D) ,1,2 Tengku Alina Tengku Ismail, ${ }^{3}$ Shaiful Bahari Ismail, ${ }^{1}$ \\ Azza Jameel Khaffaji ${ }^{4}$
}

To cite: Webair HH, Ismail TAT, Ismail SB, et al. Patient-centred infertility care among Arab women experiencing infertility: a qualitative study. BMJ Open 2021;11:e044300. doi:10.1136/ bmjopen-2020-044300

- Prepublication history and additional online supplemental material for this paper are available online. To view these files, please visit the journal online (http://dx.doi.org/10. 1136/bmjopen-2020-044300).

Received 05 September 2020 Revised 15 April 2021 Accepted 27 April 2021

A) Check for updates

(c) Author(s) (or their employer(s)) 2021. Re-use permitted under CC BY-NC. No commercial re-use. See rights and permissions. Published by BMJ.

${ }^{1}$ Family Medicine Department, School of Medical Sciences, Health campus, Universiti Sains Malaysia, Kubang Kerian, Kelantan, Malaysia

${ }^{2}$ Family Medicine Department, Hadhramout University College of Medicine, Al Mukalla, Hadhramout, Yemen

${ }^{3}$ Community Medicine Department, School of Medical Sciences, Health campus, Universiti Sains Malaysia, Kubang Kerian, Kelantan,

Malaysia

${ }^{4}$ Obstetrics \& Gynaecology, King Abdulaziz Hospital and Oncology Center, Jeddah, Makkah, Saudi Arabia

Correspondence to Dr Hana Hasan Webair; hhwebair@gmail.com

\section{ABSTRACT}

Objective The current study aims to define patientcentred infertility care (PCIC) from the perspective of Arab women with infertility.

Design Semistructured in-depth telephone interviews. Setting Hospitals providing infertility care, Jeddah, Saudi Arabia.

Participants Arab women who received infertility treatment during the 6 months preceding the interview at any hospital in Jeddah, Saudi Arabia. Interviews were conducted with Arab women experiencing infertility from January 2017 to December 2018. A purposive sample of 14 women were included in the final analysis with maximum variation.

Results Participants highlighted nine important PCIC dimensions. Of these, four were agreed on by all participants: accessibility, minimising cost, information and education, and staff attitudes and communication. The remaining five dimensions were staff competence, physical comfort, privacy, psychological and emotional support, and continuity and coordination of care. The concept of PCIC was related to three major contributors: participants' demographics, patient experience with infertility care and health-seeking behaviour.

Conclusions The current study provided nine PCIC dimensions and items, which can guide efforts to improve the quality of infertility care in Arab countries in two ways: first, by raising infertility care providers' awareness of their patients' needs, and second, by developing a validated tool based on the dimensions for measuring PCIC from Arab patients' perspective. Clear differences between the Arab and the European PCIC model were found. Our findings concluded that women continued to exhibit basic unmet needs.

\section{INTRODUCTION}

Infertility is a worldwide public health concern. ${ }^{1}$ Globally, the estimated infertility rate ranges from $3.5 \%$ to $26.4 \%$; however, the burden of infertility is higher in developing countries where 1:4 couples experience fertility problems in their reproductive lives. $^{2-4}$

The infertility care journey is invariably long and emotionally and psychosocially stressful. ${ }^{5}{ }^{6}$ Couples experiencing infertility frequently face difficulty in accessing

\section{Strengths and limitations of this study}

This study defined for the first time the concept of patient-centred infertility care from Arab women's perspective by using a qualitative approach.

- The study included women only, so the applicability of this concept to men is not appropriate.

- Our study was limited by being conducted in a single city; therefore a multicentre, cross-cultural study may provide results which are more generalisable.

infertility care-especially assisted reproductive technologies-as access varies widely across countries and regions, and is lowest in lower-income and middle-income countries. ${ }^{7}$

Previously, conceptualisations of quality of infertility care focused on outcome measures. ${ }^{89}$ However, this focus is changing, as patient-centred care (PCC) is being increasingly recognised as important for high-quality infertility care. ${ }^{10-12}$ Patient-centred infertility care (PCIC) was studied among European couples experiencing infertility, ${ }^{13}{ }^{14}$ and the following 10 dimensions were identified: information provision, competence of clinic and staff, continuity and transition, coordination and integration, accessibility, physical comfort, attitude of and relationship with staff, communication, patient involvement and privacy, and emotional support. ${ }^{1013}$ These dimensions provided the basis and structure of the Patient-Centredness Questionnaire Infertility, validated for use among European populations. $^{12}$

A literature review conducted in 2017 failed to define PCIC from the perspective of Arab patients experiencing infertility; thus, the question remained unanswered. ${ }^{15}$ What was validated in Europe might not be the case in the Arab world due to regional and cultural differences believed to affect infertility care, including counselling and treatment modalities. ${ }^{16}$ Thus, we aimed to define PCIC from the perspective of Arab women with infertility. 


\section{METHODS}

\section{Design}

This is a qualitative study using in-depth interviews (IDIs) to define PCIC from the perspective of Arab women experiencing infertility. PCIC is defined as infertility care that considers women's preferences, needs, and values, and entails their participation in all clinical decisions. ${ }^{10}$ Ethical approval was obtained then continuing review application of the protocol was carried out yearly before data collection, which was conducted during the period 2017-2018. Written informed consent was obtained from all participants.

\section{Study population}

Between January 2017 and December 2018, IDIs were conducted in Jeddah, Saudi Arabia. Inclusion criteria were Arab women who had received medical treatment for infertility during the 6 months preceding the interview, at any hospital in Jeddah. A purposive sample of 14 women were recruited, with maximum variation. The motive behind maximum variation sampling was to gain greater insight into PCIC by viewing it from different angles. Variations included age group, level of education, occupation, duration of marriage and infertility, infertility type, number of living children, treatment used, health facility visited and duration of seeking infertility care. Participants were recruited purposefully until data saturation was reached and no new themes emerged.

\section{Data collection and analysis}

IDIs were conducted via telephone. Researchers have found no real difference in the quality of data or the published papers when using telephone interviews compared with face-to-face interviews. ${ }^{1}$ In addition, telephone interviews have many advantages, including being less intrusive, more cost effective, less time consuming and involving less interview tension. ${ }^{2}$ During the participant recruitment phase, the invited women reported that they would prefer telephone interviews over face-to-face ones. This interview method provided more anonymity and autonomy as the participants were asked to mention their given name only and they could choose the time, and the phone number to be called on. The length of the IDIs ranged from 45 to $90 \mathrm{~min}$. All IDIs were conducted by a female researcher, who is a family physician with experience in qualitative data collection (HHW). An interview guide was used to collect data flexibly. Initially, the researcher introduced herself as a researcher and family physician interested in PCC. Then, each participant was provided with a consent form, which included a clear explanation of the aim of the study, and was asked to sign the form if she agreed to participate. The IDI guide consisted of two parts: part 1 assessed participants' demographics, and part 2 included a question regarding medical care received, followed by six open-ended questions regarding PCIC (online supplemental file 1). Each interview was audiorecorded, transcribed verbatim, translated from Arabic to English, then imported into NVivo V.12 for analysis.

\section{Inductive thematic analysis}

Inductive coding thematic analysis was applied to describe, compare and relate findings, as patient centredness had not been defined from Arab patients' perspective. The first step in the analysis was reading and re-reading the transcripts several times to become familiar with emerging data. At this stage, notes were written by hand, summarising the main points and our initial impressions. These notes focused on mapping out patients' experiences with fertility care received and their definitions of PCIC. Next, HHW and TATI used line-byline coding independently for each IDI. Authors HHW and TATI examined the data to identify and agree on common themes, which were analysed independently, while continuously developing and modifying codes. When we completed coding for five IDIs, findings were discussed and modified before moving forward. Discrepancies were discussed until consensus was reached. If consensus was not reached, that point was discussed with the third author (SBI). Then, codes were categorised into preliminary subthemes and themes.

Data saturation was reached on completion of fourteen IDIs, yielding 148 codes. Preliminary themes were continuously reviewed and modified until we developed the final themes. Matrix queries produced by NVivo were used to display the frequency of codes occurring within the text or of codes and participants' characteristics. This matrix enabled us to assess the degree of agreement among participants and the nature of the associations.

Four methods were adopted to enhance validity. First, different aspects of the same concept were assessed. The IDI guide included six questions about PCIC; however, they were worded differently asking about participants' positive and negative perceptions of care experience, what they needed from infertility care, what would be an optimal situation, and finally, a direct question about participants' definitions of PCIC. Second, source triangulation was used by ensuring maximum variations in the sample to explore PCIC from different viewpoints. Additionally, two gynaecologists were asked about concerns in infertility care expressed by participants, such as waiting times and financial aspects. In addition, after completion of data analysis, the PCIC dimensions that emerged from the current study were compared with those identified by European participants, the only available PCIC dimensions from patients' perspectives before our study. Third, analyst triangulation was applied, with three analysts involved in reviewing the findings. Fourth, respondents' validation was sought. After data analysis, we sent participants a summary of the PCIC dimensions and their items. All agreed that the dimensions they preferred were included. Two respondents stressed avoiding long waiting times and providing appropriate appointments for the purpose of follow-up visits. The results are reported 
Table 1 Characteristics of participants involved in in-depth interviews $(n=14)$

\begin{tabular}{|c|c|c|}
\hline \multicolumn{2}{|c|}{ Participant characteristics } & \multirow{2}{*}{$\frac{\text { No (\%) }}{5(35.71)}$} \\
\hline Age, year & $25-$ & \\
\hline & $30-$ & $3(21.43)$ \\
\hline & $35-$ & $3(21.43)$ \\
\hline & $40-45$ & $3(21.43)$ \\
\hline \multirow[t]{2}{*}{ Residency } & Jeddah & $10(71.43)$ \\
\hline & Out of Jeddah & $4(28.57)$ \\
\hline \multirow{4}{*}{$\begin{array}{l}\text { Duration of marriage, } \\
\text { year }\end{array}$} & $1-$ & $7(50.00)$ \\
\hline & $5-$ & $3(21.43)$ \\
\hline & $10-$ & $1(7.14 \%)$ \\
\hline & $15-20$ & $3(21.43)$ \\
\hline \multirow{4}{*}{$\begin{array}{l}\text { Duration of infertility, } \\
\text { year }\end{array}$} & $1-$ & $7(50.00)$ \\
\hline & $3-$ & $5(35.71)$ \\
\hline & $6-$ & $1(7.14)$ \\
\hline & 9 & $1(7.14)$ \\
\hline \multirow{3}{*}{$\begin{array}{l}\text { Duration of seeking } \\
\text { infertility care, year }\end{array}$} & $1-$ & $8(57.14)$ \\
\hline & $3-6$ & $4(28.57)$ \\
\hline & $>6$ & $2(14.29)$ \\
\hline \multirow[t]{3}{*}{ No of living children } & 0 & $8(57.14)$ \\
\hline & 1 or 2 & $5(35.71)$ \\
\hline & 3 or more & $1(7.14)$ \\
\hline \multirow[t]{2}{*}{ Type of infertility } & Primary & $5(35.71)$ \\
\hline & Secondary & $9(64.29)$ \\
\hline \multirow[t]{2}{*}{ Pregnant now } & Yes & $2(14.29)$ \\
\hline & No & $12(85.71)$ \\
\hline \multirow[t]{4}{*}{$\begin{array}{l}\text { Type of treatment } \\
\text { used }\end{array}$} & $\begin{array}{l}\text { Medical (OI, } \\
\text { hyperprolactinaemia) }\end{array}$ & $13(92.86)$ \\
\hline & IUI & $1(7.14)$ \\
\hline & ICSI/IVF & $3(21.43)$ \\
\hline & Surgical & $6(42.86)$ \\
\hline
\end{tabular}

ICSI/IVF, intracytoplasmic sperm injection/in vitro fertilisation; IUI, intrauterine insemination; OI, ovulation induction.

according to the Consolidated Criteria for Reporting Qualitative Research ${ }^{17}$ (online supplemental file 2).

\section{Patient and public involvement}

Patients were involved in the conduct and reporting of this research. Please refer to the Methods section for further details.

\section{RESULTS}

Table 1 shows participants' demographics. Thematic analysis yielded three themes: (1) PCIC dimensions, (2) PCIC definition and patient experiences and (3) PCIC and health-seeking behaviour (HSB). The third theme included six subthemes. As shown in figure 1, there was an interaction between participants' definitions of PCIC and patient experience, HSB and their sociodemographic characteristics.

\section{PCIC dimensions}

Nine PCIC dimensions were identified from 14 IDIs. Table 2 summarises the dimensions and each of their items, ordered following a logical stream, similar to what patients experience during infertility care.

All participants mentioned four dimensions as important elements of PCIC: accessibility (short waiting times), minimising cost (providing infertility care at a reasonable, affordable cost), information and education (providing relevant information with adequate explanation) and staff attitudes and communication (treating patients and other staff with dignity and respect). Information from obstetricians/gynaecologists supported participants' perspectives regarding waiting times and costs. Despite being noted as important dimensions, participants' preferences varied regarding maximum waiting times, relevant information and privacy during infertility care. These preferences were affected to some extent by participants' educational level, infertility care experience and marital relationship quality. Table 3 compares these dimensions with the European PCIC model.

\section{PCIC definition and patient experience}

When asked to define PCIC, participants provided short definitions focused on a few points, although they mentioned much more during the preceding questions about their infertility care experience. The panel (online supplemental file 3) shows participants' definitions of PCIC and summarises each participant's experience.

Most participants had a dominant issue during infertility care. These issues were related to the medical care itself or sociodemographic circumstances. Participant experience shaped participants' definitions of PCIC the most, as shown in the panel.

\section{PCIC and HSB}

PCIC dimensions influenced participants' HSB, as suggested by the following subthemes.

\section{Self-medication}

Participants practiced two methods of self-medication: obtaining non-prescribed medications, and using traditional or herbal medicines.

The first method is not a responsible form of selfmedication, based on the WHO's definition. ${ }^{18}$ One patient used ovulation induction medications (clomiphene citrate tablets, menotropin injections and choriomon injections) in high doses, reaching double the dosage prescribed by her physicians. All were prescription-only medications.

I used to order images for myself for ovulation. I knew the size of the egg, they (doctors) got annoyed! 


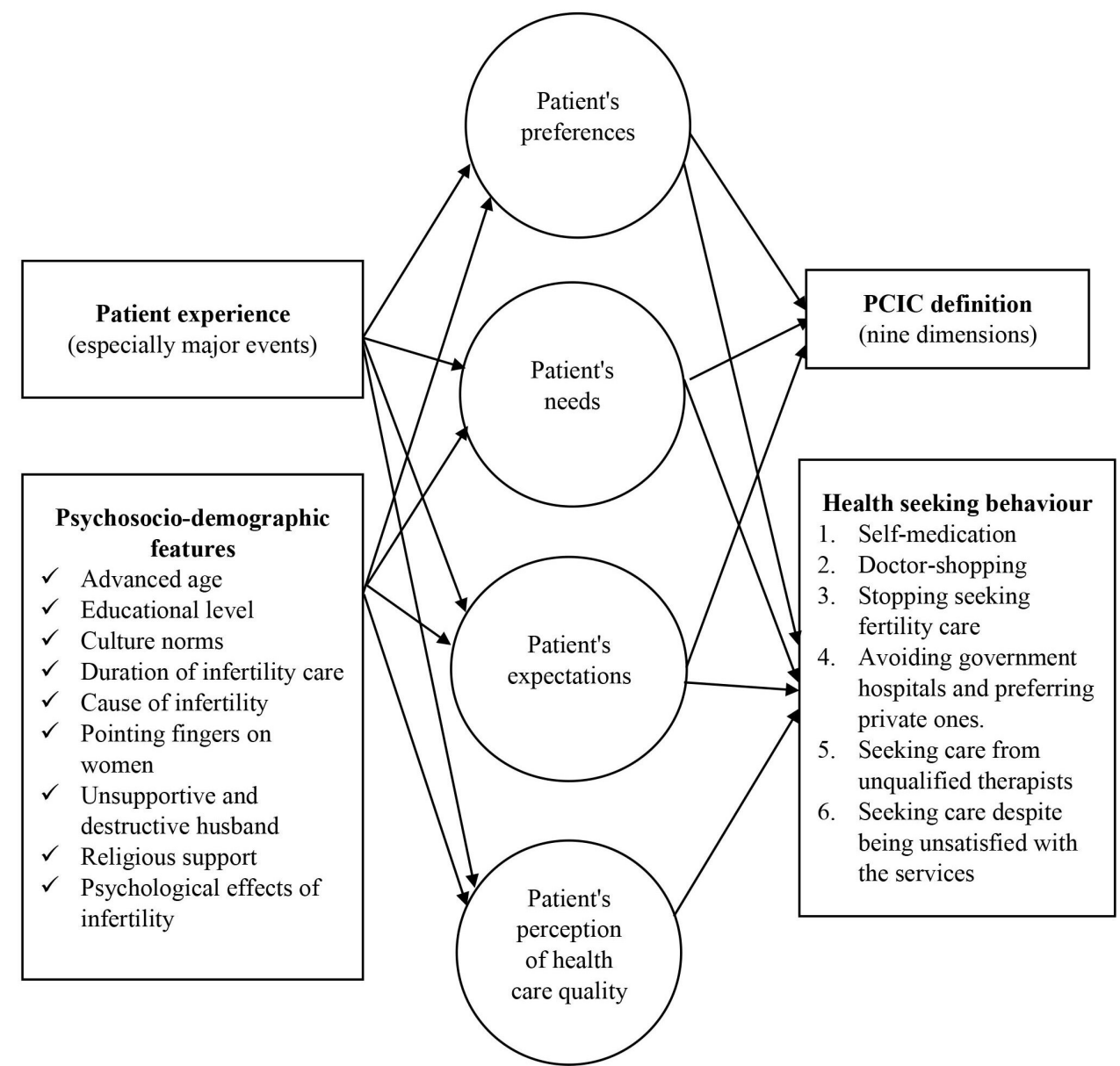

Figure 1 Diagram shows the interaction between PCIC definition (circles) and patient experience, psychosocio-demographic features and health-seeking behaviour (rectangles). PCIC, patient-centred infertility care.

Yes, I would get the image and ask for a trigger shot, because sometimes we had sex before meeting the doctor. I wanted to know, but sometimes you do not find the answer you are looking for.... Now I knew that if the egg was more than 15, I should take the trigger shot, Participant 10, secondary infertility

She did not ask her doctors to increase the dose, because she felt that they were 'fed up' with her many questions and requests. Additionally, appointments were far apart; therefore, if she waited to meet her physician each time to obtain the prescription, she would have a very long treatment journey.

For the second method, most participants (12 out of 14) used traditional and/or herbal medicine during infertility care. Remedies included herbs, honey, cupping therapy (Hijamah), massage and Qur'anic verses read to achieve improvement (Roqia). Participants had different attitudes towards this kind of medicine. Some preferred it over modern medicine, as they considered modern medicines to be harmful chemicals, while traditional medicine is natural, and therefore, harmless. Others were cautious with herbs, as safe and effective dosage is unknown. The majority preferred to use both traditional and modern medicine, as traditional medicine is safe and accessible, and modern medicine failed to solve several of their infertility problems.

\section{Doctor shopping}

Some participants would visit more than one infertility doctor for the same complaint during the same time period. Participant 8 used to seek four different doctors' opinions before undergoing any procedure, to ensure it was the correct decision. This patient had recurrent pregnancy loss and discovered she was not examined properly, which eventually cost her a lot of money in diagnosing and treating the cause. Participant 12 was following up with an infertility doctor, then decided to shift to another doctor after failed in vitro fertilisation (IVF) due to low sperm quality. The reason was a lack of honesty, as this participant knew indirectly after her failed IVF procedure that there was a high possibility of IVF failure; however, the physician did not disclose that. Additionally, participants sought second opinions while still following up with their primary physician because their physician did not give a contact number, provided inadequate information or did not disclose all available options. Some women changed physicians, or even hospitals, due to failure to provide a clear plan from the start, failure to reach a diagnosis and 
Table 2 Patient-centred infertility care (PCIC) dimensions from the perspective of Arab women experiencing infertility

\section{PCIC}

dimensions PCIC items

Accessibility Availability of appropriate appointments

Ease of access to the healthcare facility

Smoothness of the process of booking appointment, registration and workflow

Justice in handling appointments and patient access

Providing easy access to doctors through phone and online consultations

Short waiting time

Vacancy (no overcrowding)

Minimising cost Covering infertility care cost by insurance

Provision of infertility management in public sector free of charge

Providing infertility care at reasonable, affordable cost

\begin{tabular}{|c|c|}
\hline \multirow{5}{*}{$\begin{array}{l}\text { Physical } \\
\text { comfort }\end{array}$} & Cleanliness \\
\hline & Comfortable environment \\
\hline & Assistance and provision of care \\
\hline & Pain avoidance and relieve \\
\hline & Single dose, less frequent medication doses \\
\hline \multirow[t]{8}{*}{ Privacy } & $\begin{array}{l}\text { Providing care in special department for women } \\
\text { with infertility }\end{array}$ \\
\hline & Providing female doctors \\
\hline & $\begin{array}{l}\text { Avoiding over or unnecessarily exposing intimate } \\
\text { parts of patient's body }\end{array}$ \\
\hline & $\begin{array}{l}\text { Considering differences in privacy mean from } \\
\text { patient to another }\end{array}$ \\
\hline & $\begin{array}{l}\text { Ensuring minimal interruption and number of } \\
\text { people in, no men or other patients }\end{array}$ \\
\hline & $\begin{array}{l}\text { Taking patient permission before allowing more } \\
\text { people in }\end{array}$ \\
\hline & $\begin{array}{l}\text { Preferring nobody knows about patient's infertility } \\
\text { issues }\end{array}$ \\
\hline & $\begin{array}{l}\text { Considering differences in the preferences } \\
\text { regarding husband involvement }\end{array}$ \\
\hline \multirow{6}{*}{$\begin{array}{l}\text { Staff } \\
\text { attitude and } \\
\text { communication }\end{array}$} & $\begin{array}{l}\text { Treating patient and other staff with dignity and } \\
\text { respect }\end{array}$ \\
\hline & Staff truthfulness \\
\hline & Avoiding materialistic behaviour \\
\hline & Practicing medicine in love and dedication \\
\hline & Being so patient \\
\hline & Religious approach \\
\hline \multirow{5}{*}{$\begin{array}{l}\text { Staff } \\
\text { competence }\end{array}$} & Well-known doctors \\
\hline & $\begin{array}{l}\text { Proper and accurate evaluation; history, } \\
\text { examination and investigations as needed }\end{array}$ \\
\hline & Understanding the patient fast and well \\
\hline & Providing diagnosis and curative solutions \\
\hline & Avoiding medications with bad side effects \\
\hline
\end{tabular}

Continued
Table 2 Continued

Providing comprehensive and personalised care Qualification

$\begin{array}{ll}\text { Information } & \text { Giving and taking, encouraging discussion and } \\ \text { and education } & \text { negotiation }\end{array}$

and education negotiation

Providing relevant information about the patient status, progress and prognosis

Disclosure and clarification of all treatment options Providing information on processes of care before each step, what to expect before, during,andafter procedures, then home care, plan of care, and follow-up

Informing patient about the use, expected effects and possible side effects before starting treatment

Providing relevant information with adequate explanation

Talking to patients with simple understandable language

Welcoming patient questions and providing answers throughout healthcare journey

Raising health awareness and education through school education, doctors in clinics and campaigns

Considering the patient with long experience as an expert in her case

Psychological Listening to patients

and emotional

support

\begin{tabular}{|l} 
Considering the patient's personal situation \\
Preparing patient psychologically throughout her \\
treatment journey \\
Giving patient realistic hope \\
Avoiding using destroying words or attitude, or \\
pointing finger at the patient \\
Ensuring ongoing support and motivation \\
Continuity and \\
coordination of $\begin{array}{l}\text { Studying the patient case well including proper } \\
\text { care }\end{array}$ \\
$\begin{array}{l}\text { documentation and up-to-date file review } \\
\text { Treating couple as one case } \\
\text { Developing and sharing detailed plan of care from } \\
\text { the start }\end{array}$ \\
$\begin{array}{l}\text { Ongoing planning, follow-up, and coordination of } \\
\text { care hand on hand with the patient based on health } \\
\text { situations and patient needs }\end{array}$ \\
$\begin{array}{l}\text { Providing follow-up with the same doctor } \\
\text { Including doctors from same specialty and other } \\
\text { specialties as needed }\end{array}$ \\
Facilitating the shortest treatment journey \\
Encouraging female's check-up before marriage \\
\hline
\end{tabular}

order important tests, doctors' offensive behaviour, poor communication or physical discomfort.

Stopping infertility care

Some participants stopped seeking infertility care, although they still needed it. Women can face many obstacles during infertility care, and they commonly try to overcome these obstacles to get pregnant. The major obstacle 
Table 3 Comparison between the Arab and European patient-centred infertility care (PCIC) dimensions

\begin{tabular}{ll}
\hline Arab PCIC dimensions & European PCIC dimensions \\
\hline 1. Accessibility & 1. Accessibility \\
2. Minimising cost* & 2. Physical comfort \\
3. Physical comfort & $\begin{array}{l}\text { 3. Patient involvement* and } \\
\text { privacy }\end{array}$ \\
4. Privacy & $\begin{array}{l}\text { 4. Attitude of and relationship with } \\
\text { staff }\end{array}$ \\
$\begin{array}{l}\text { 5. Staff attitude and } \\
\text { communication }\end{array}$ & 5. Communication
\end{tabular}

5. Communication

6. Staff competence $\quad$ 6. Competence of clinic and staff
$\begin{aligned} & \text { 7. Information and } \\ & \text { education }\end{aligned}$
education

\begin{tabular}{ll}
$\begin{array}{l}\text { 8. Psychological and } \\
\text { emotional support }\end{array}$ & 8. Emotional support \\
$\begin{array}{l}\text { 9. Continuity and } \\
\text { coordination of care }\end{array}$ & 9. Coordination and integration, \\
& 10. continuity and transition \\
\hline
\end{tabular}

*Indicates the dimension mentioned in one model only.

that led participants to stop seeking care was cost, which was described as 'horrible'. Other obstacles, such as lack of support and cooperation from husbands, also contributed, but did not lead to complete discontinuation.

Images and tests and so-on!! we paid a large sum of money! And not covered by insurance... Actually, the cost should not be huge. It should not be purely materialistic, Participant 13, primary infertility.

\section{Avoiding public hospitals and preferring expensive private care}

Although cost was a major barrier to accessing infertility care, several participants surprisingly chose to seek care in the expensive private sector. The reasons included poor environment in government hospitals, difficulty booking appropriate appointments and long waiting times. An important factor was the unavailability of infertility units and important services (eg, IVF) in general government hospitals. Therefore, couples experiencing infertility received care in the general obstetrics/gynaecology clinics.

So, I never mind paying the blood of my heart (all what I have) to go to a place where I'm comfortable psychologically while I'm receiving care, in order to not end up with a bad experience or a bad smell in my memory (the bad smell in some low-quality hospitals), Participant 5, primary infertility.

Seeking care from unqualified therapists, which could cause harm Participants sought care from unknown individuals who posted on social media. Participant 10 followed a woman on Instagram who posted prescriptions related to an ovulation induction technique involving three drugs.
Participant 12 received an advertisement online from a person claiming to have medicines that are not available in Saudi Arabia that he could ship at a high cost. That medicine was not licensed by the the Food and Drug Administration (FDA) and not sold in pharmacies anywhere. Participant 7 visited an unlicensed massage therapist who claimed she could correct the position of one's womb. These behaviours were attributed to the failure of physicians to reach a diagnosis or successfully treat the problem. Furthermore, the unqualified individuals tended to communicate well, take a detailed history, provide adequate information, and were easy to access and highly responsive.

Imagine, he asked me questions I'd never been asked by any of the doctors I'd visited here! Participant 12, primary infertility.

\section{Seeking care despite dissatisfaction with services}

Achieving some dimensions of PCIC, such as a doctor's competence and communication skills, offset the absence of others, thereby encouraging participants to seek care. Many participants visited an infertility care facility they did not like because they were looking for specific physicians. Thus, a good doctor's communication skills and competence supported seeking infertility care and encouraged participants to temporarily overlook physical discomfort.

\section{DISCUSSION}

In the current study, PCIC was defined across nine dimensions, from the perspectives of Arab women experiencing infertility. All participants agreed on four dimensions: accessibility, minimising cost, information and education, and staff attitudes and communication. The five remaining dimensions were staff competence, physical comfort, privacy, continuity and coordination of care, and psychological and emotional support. PCIC had three major contributors: participants' demographics, patient experience with infertility care and HSB.

These PCIC dimensions were similar, to some extent, to those developed by Dancet $e t$ al from across Europe (European PCIC-model; table 3). ${ }^{14}$ There were substantial differences, however. First, minimising cost was highly valued by our participants, but absent in the European model. Similarly, patient involvement, which was included in the European model, was not mentioned by our participants. Second, prioritisation of the dimensions differed. For example, accessibility, a dimension agreed on by all our participants, was among the least prioritised by European participants. Third, even dimensions included in both models showed some differences in preferences and needs between Arab and European groups. For example, concerning provision of information, our participants focused on deficient information during the treatment at the health facility; however, the European model included the more ambitious addition of receiving information on media. These three differences reflect Arab women's low 


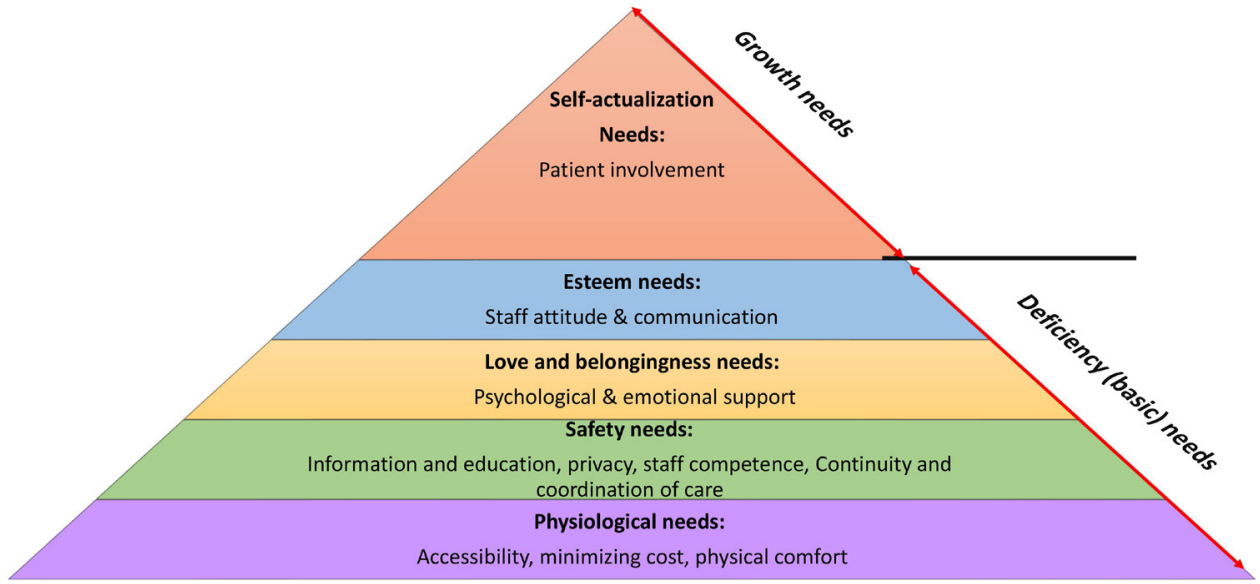

Figure 2 Maslow's Hierarchy of patient-centred infertility care.

expectations in relation to European women. They mainly focused on unmet needs, which shaped the majority of PCIC definitions in our study.

Maslow's hierarchy of needs explains this pattern well. ${ }^{19}$ It is a motivational theory comprising a five-tier model of human needs; needs lower in the hierarchy must be satisfied before individuals can attend to higher needs. These needs are divided into deficiency (basic) needs (physiological, safety, love and belonging, and esteem) and growth needs (self-actualisation). Self-actualised people use their full potential. ${ }^{19}$ Figure 2 shows Maslow's hierarchy of needs, as adapted to PCIC. Notably, it was difficult to sort dimensions by need categories when adapting Maslow's hierarchy to PCIC, as each dimension could include a mixture of deficiency and growth needs. For example, information provision could be a basic need (eg, how to use a medication) or a growth need (eg, detailed knowledge on IVF procedures to facilitate decision-making). The hierarchy indicates that participants focused on deficiency needs, as all nine dimensions are within the deficiency needs zone and did not reach self-actualisation. The IDI transcripts showed low expectations among participants, with few exceptions. Based on Maslow's hierarchy, this indicates that participants' deficiency needs were not covered, and they continued to struggle to receive infertility care. Thus, PCIC is expected to help Arab women experiencing infertility satisfy their deficiency needs and become motivated to achieve selfactualisation, thereby empowering them to participate in infertility care.

The current study found that the PCIC definition was shaped by the patient experience with infertility care. This finding indicates that this definition is dynamic and not static. The patient may provide different preferences if the concept was to be explored at different time points.

To the best of our knowledge, this is the first study that showed a possible association between PCC and HSB. Generally, seeking infertility medical care has been shown to relate to prior experience with doctors. ${ }^{20}$ In line with our findings, self-medication has been associated with some dimensions of PCC, including accessibility (especially lack of insurance coverage), ${ }^{21}{ }^{22}$ knowledge, ${ }^{23}$ physical comfort ${ }^{23}$ and dissatisfaction with healthcare providers. ${ }^{18}$ Huppelschoten et al found no relation of PCIC with drop-out. ${ }^{24}$ Our findings suggested the opposite, as PCIC was related to discontinuation of treatment and changing doctors or hospitals. Sansone and Sansone supported that inconvenient clinician factors promote doctor shopping. ${ }^{25}$ Unlike other forms of HSB, using traditional and spiritual treatments was related to beliefs and preferences that favoured such treatments over conventional medicine, in line with previous studies. ${ }^{202627}$

\section{Limitations}

Regarding limitations, our study was conducted in a single city. Collecting data from across Saudi Arabia, or more than one country in the Arab world, was infeasible due to a lack of funding. The current study highlighted the possible effect of PCIC on HSB; however, this association could not be confirmed due to the nature of qualitative research. Future quantitative studies are needed to confirm the association and, if proven, to consider HSB as an indicator of PCIC.

\section{CONCLUSION}

This study identified nine PCIC dimensions and items, which reflect the definition of PCIC and can guide efforts to improve the quality of Arab infertility care. Clear differences between the Arab and the European PCIC model were found. Our findings led us to conclude that women continue to exhibit unmet basic needs. We hope this study will prompt further research regarding PCIC in the Arab world and thereby provide more implications for improving the quality of infertility care and quality of life for women who experience infertility. This study created a list of PCIC dimensions and items but did not develop a tool to measure PCIC. Thus, further work is recommended to develop a validated tool for measuring PCIC from Arab patients' perspectives.

Acknowledgements We would like to thank the women and gynaecologists who participated in the study. We also would like to thank Editage (www.editage.com) for English language editing of our manuscript. 
Contributors HHW, TATI and SBI contributed to the study design. HHW and AJK collected the data. HHW, TATI, SBI and AJK performed the data analysis and interpretation. HHW wrote the first draft of the article and all authors contributed to subsequent revisions.

Funding The authors have not declared a specific grant for this research from any funding agency in the public, commercial or not-for-profit sectors.

Competing interests None declared.

Patient consent for publication Not required.

Ethics approval The study proposal was reviewed and approved by the IRB of the Department of Medical Research and Studies, Directorate of Health Affairs, Ministry of Health, Jeddah, Saudi Arabia (number A00306); and the Human Research and Ethics Committee of Universiti Sains Malaysia (Number USM/ JEPeM/15020056, Date 03/11/2015). The study was performed in accordance with the ethical standards as laid down in the 1964 Declaration of Helsinki and its later amendments.

Provenance and peer review Not commissioned; externally peer reviewed.

Data availability statement All data relevant to the study are included in the article or uploaded as online supplemental information.

Supplemental material This content has been supplied by the author(s). It has not been vetted by BMJ Publishing Group Limited (BMJ) and may not have been peer-reviewed. Any opinions or recommendations discussed are solely those of the author(s) and are not endorsed by BMJ. BMJ disclaims all liability and responsibility arising from any reliance placed on the content. Where the content includes any translated material, BMJ does not warrant the accuracy and reliability of the translations (including but not limited to local regulations, clinical guidelines, terminology, drug names and drug dosages), and is not responsible for any error and/or omissions arising from translation and adaptation or otherwise.

Open access This is an open access article distributed in accordance with the Creative Commons Attribution Non Commercial (CC BY-NC 4.0) license, which permits others to distribute, remix, adapt, build upon this work non-commercially, and license their derivative works on different terms, provided the original work is properly cited, appropriate credit is given, any changes made indicated, and the use is non-commercial. See: http://creativecommons.org/licenses/by-nc/4.0/.

ORCID iD

Hana Hasan Webair http://orcid.org/0000-0002-5019-8321

\section{REFERENCES}

1 Macaluso M, Wright-Schnapp TJ, Chandra A, et al. A public health focus on infertility prevention, detection, and management. Fertil Steril 2010;93:16.e1-10.

2 WHO. Sexual and reproductive health: Infertility is a global public health issue [online]. Available: https://www.who.int/ reproductivehealth/topics/infertility/perspective/en/ [Accessed 10 Nov 2019].

3 Mascarenhas MN, Flaxman SR, Boerma T, et al. National, regional, and global trends in infertility prevalence since 1990: a systematic analysis of 277 health surveys. PLoS Med 2012;9:e1001356.

4 Lemoine M-E, Ravitsky V. Toward a public health approach to infertility: the ethical dimensions of infertility prevention. Public Health Ethics 2013;6:287-301.

5 Alesi R. Infertility and its treatment-an emotional roller coaster. Aust J Gen Pract 2005;34:135.

6 Huppelschoten AG, Nelen WLDM, Westert GP, et al. Improving patient-centredness in partnership with female patients: a cluster RCT in fertility care. Human Reprod 2015;30:1137-45.
7 Adamson GD, de Mouzon J, Chambers GM, et al. International Committee for monitoring assisted reproductive technology: world report on assisted reproductive technology, 2011. Fertil Steril 2018;110:1067-80.

8 de Mouzon J, Goossens V, Bhattacharya S, et al. Assisted reproductive technology in Europe, 2006: results generated from European registers by ESHRE. Hum Reprod 2010;25:deq124:1851-62.

9 Nyboe Andersen A, Goossens V, Bhattacharya S, et al. Assisted reproductive technology and intrauterine inseminations in Europe, 2005: results generated from European registers by ESHRE: ESHRE. The European IVF monitoring programme (EIM), for the European Society of human reproduction and embryology (ESHRE). Hum Reprod 2009;24:1267-87.

10 Institute of Medicine. Crossing the quality chasm: a new health system for the 21st century. Washington, DC: National Academies Press, 2001.

11 Dancet E, Nelen W, Sermeus W. The patients' perspective on fertility care: a systematic review. Hum Reprod Update 2010:dmq004.

12 van Empel IWH, Aarts JWM, Cohlen BJ, et al. Measuring patient-centredness, the neglected outcome in fertility care: a random multicentre validation study. Human Reproduction 2010;25:2516-26.

13 Dancet EAF, Van Empel IWH, Rober P, et al. Patient-centred infertility care: a qualitative study to listen to the patient's voice. Hum Reprod 2011;26:827-33.

14 Dancet EAF, D'Hooghe TM, Sermeus W, et al. Patients from across Europe have similar views on patient-centred care: an international multilingual qualitative study in infertility care. Human Reproduction 2012;27:1702-11.

15 Webair HH, Ismail TAT, Ismail SB. Patient-centered infertility care from an Arab perspective: a review study. Middle East Fertil Soc $J$ 2018;23:8-13.

16 Lawrenz B, Coughlan C, Melado L, et al. Ethnical and sociocultura differences causing infertility are poorly understood-insights from the Arabian perspective. J Assist Reprod Genet 2019;36:661-5.

17 Tong A, Sainsbury P, Craig J. Consolidated criteria for reporting qualitative research (COREQ): a 32-item checklist for interviews and focus groups. Int J Qual Health Care 2007;19:349-57.

18 Alghanim SA. Self-medication practice among patients in a public health care system. East Mediterr Health J 2011;17:409-16.

19 Maslow A. Motivation and personality. 2nd edn. New York: Harper and Row, 1970

20 White L, McQuillan J, Greil AL. Explaining disparities in treatment seeking: the case of infertility. Fertil Steril 2006;85:853-7.

21 Pagán JA, Ross S, Yau J, et al. Self-medication and health insurance coverage in Mexico. Health Policy 2006;75:170-7.

22 Shaghaghi A, Asadi M, Allahverdipour H. Predictors of selfmedication behavior: a systematic review. Iran J Public Health 2014:43:136-46.

23 Dyer SJ. Infertility-related reproductive health knowledge and help-seeking behaviour in African countries. ESHRE Monographs 2008;2008:29-33.

24 Huppelschoten AG, van Dongen AJCM, Philipse ICP, et al. Predicting dropout in fertility care: a longitudinal study on patient-centredness. Human Reproduction 2013;28:2177-86.

25 Sansone RA, Sansone LA. Doctor shopping: a phenomenon of many themes. Innov Clin Neurosci 2012;9:42-6.

26 Aydin S, Bozkaya AO, Mazicioglu MM. What influences herbal medicine use?-prevalence and related factors. Turk J Med Sci 2008;38:455-63.

27 Nahar P. Health seeking behaviour of childless women in Bangladesh: an ethnographic exploration for the special issue on: loss in child bearing. Soc Sci Med 2010;71:1780-7. 